\title{
Systematic screening to integrate reproductive health services in India
}

N.P. Das

Urvi Shah

Varsha Chitania

Pratibha Patel

M.E. Khan

Population Council

See next page for additional authors

Follow this and additional works at: https://knowledgecommons.popcouncil.org/departments_sbsr-rh

Part of the Demography, Population, and Ecology Commons, International Public Health Commons, Public Health Education and Promotion Commons, and the Women's Health Commons How does access to this work benefit you? Let us know!

\section{Recommended Citation}

Das, N.P., Urvi Shah, Varsha Chitania, Pratibha Patel, M.E. Khan, Anurag Mishra, and James R. Foreit. 2005. "Systematic screening to integrate reproductive health services in India," FRONTIERS Final Report. Washington, DC: Population Council. 
Authors

N.P. Das, Urvi Shah, Varsha Chitania, Pratibha Patel, M.E. Khan, Anurag Mishra, and James R. Foreit 


\title{
Systematic Screening to Integrate Reproductive Health Services in India
}

\author{
N.P. Das, Urvi Shah, Varsha Chitania \\ Population Research Centre, University of Vadodara \\ Pratibha Patel \\ The Vadodara Municipal Corporation \\ M.E. Khan, Anurag Mishra, and James R. Foreit \\ Frontiers in Reproductive Health Program
}

August 2005

This study was funded by the U.S. AGENCY FOR INTERNATIONAL DEVELOPMENT (USAID) under the terms of Cooperative Agreement number HRN-A-00-98-00012-00, Population Council In-house Project No. 5800 53078, and Subagreement No. AI04.30A. The opinions expressed herein are those of the authors and do not necessarily reflect the views of USAID. 


\section{ABSTRACT}

This study tested the effectiveness of a systematic screening technique in integrating reproductive health services at the provider level. The study was conducted in large public clinics and small health posts in the city of Vadodara, India. The objective was to determine if women screened during clinic visits received more services, appointments, and referrals per visit than women who were not screened. The intervention consisted of the use of a brief screening algorithm, followed by the offer of the needed services. The study used a pre-test/post-test experimental and control group design.

In experimental group clinics the number of services per visit increased by 22 percent while control clinics experienced a slight decrease. The additional services most frequently provided in experimental clinics were family planning and vaccinations. The effect of systematic screening was smaller in health posts than in clinics. In experimental posts, services per visit increased by nine percent compared to a decrease of 16 percent among controls. The municipality of Vadodara will begin systematic screening in all clinics. Gujarat state, where Vadodara is located, also plans to adopt the intervention. 


\section{INTRODUCTION}

Many program clients, especially women with young children, have multiple needs for preventive and curative reproductive health services. Typically, health providers deliver only the service requested by the client and do not identify other needs. Additionally clients may be unaware that they may need additional services, or that the services they need are available. In any case, the client often leaves the facility with unmet reproductive health needs and the service provider misses an opportunity to render those services.

One solution to the problem of lack of integration may be to identify the client's needs and desires for reproductive health services when she first arrives for a visit, and to provide those services to her, either during the same visit, at a scheduled subsequent visit, or through referral to another facility. This solution is embodied in the recommendation of the 1994 Cairo International Conference on Population and Development (ICPD) Program of Action to promote the delivery of integrated reproductive health services. Integration is defined as the proactive provision of multiple reproductive health services in the same facility at the same time (Foreit, Hardee, and Agarwal 2002).

The Reproductive and Child Health programme in India is shifting from a focus on controlling population size to a focus on addressing health needs. The new programme incorporates child survival, safe motherhood, and STI/HIV services, as well as family planning. Although the integration of services has taken place on a temporal and facility level, health authorities in the city of Vadodara felt that additional improvements in integration could be achieved at the provider level by having staff identify clients' unmet needs and offer additional reproductive health services at the client's visit.

The Vadodara municipal government tested a simple algorithm for systematically screening women visiting clinics for unmet needs and, when detected, offering them the appropriate service, appointment or referral. Previously, the systematic screening technique has been successful at increasing services per visit in five countries in Africa and Latin America - Bolivia (Foreit, Vernon and Hamel 2005), Guatemala and Mexico (Vernon and Foreit 1999), Peru (León et al. 1998), and Senegal (Sanogo et al. 2005). This study was conducted in large, municipalityoperated public health clinics and their smaller satellite health and nutrition posts called "Anganwadi” Centers (AWCs). The municipal government hypothesized that women whose health needs were identified by a systematic screening instrument would receive more services per visit than women receiving reproductive health services in facilities using current routine procedures only.

\section{METHODOLOGY}

Participants and Design: Women attending reproductive health services in eight Vadodara clinics and 111 AWCs during the period July - October 2004 participated in the study. All participants gave verbal informed consent. The research design was a pre-test/post-test experimental and control group comparison. Eight of 18 municipal clinics were randomly selected for the study, and then randomly assigned to intervention and control groups. These clinics provide maternal and child health, reproductive health and family planning services, as 
well as general curative services. The clinics are staffed by a female medical officer, a female health visitor, two to three auxiliary nurse-midwives, and a vaccinator. The clinics do not have laboratories, thus cases requiring laboratory testing are referred to hospitals. Preventive care services such as immunization and family planning are offered once a week at a special clinic, as well as daily on request. AWCs are administratively attached to the health clinics. AWCs attached to control clinics formed the AWC control group, while those attached to experimental clinics formed the AWC intervention group. There were 56 experimental and 55 control AWCs.

Intervention: The intervention consisted of: (1) training all experimental group service providers in the use of a screening instrument to identify the reproductive health and child survival needs of women 15-49 years of age seeking care for themselves or their children less than 5 years of age; and (2) offering the needed services during the same visit, at a future appointment at the same center, or by referral to another facility if identified needs could not be met at the current visit or in the same facility.

Dependent Variables: Three dependent variables were measured: (1) number of services provided per visit, (2) number of appointments per visit, and (3) referrals per visit. The most important dependent variable was the number of services provided per visit, since it was not possible to track the results of appointments and referrals. In both clinics and AWCs, the services for which clients were screened included antenatal care, infant and childcare, family planning, reproductive health, vaccination, and other services. As is often the case with service statistics systems, service categories do not provide much insight into the type of services actually provided. For example, "other services" actually consist of the distribution of iron tablets and vitamin A as well as a variety of curative services. Because services per visit are not normally distributed, we used a non-parametric test, the Mann-Whitney U, to test for significant differences between groups. Analyses were also conducted to determine the extent to which detected service needs were addressed during the study.

Procedure: The systematic screening instrument is a single page form that the provider first registering the client at the facility uses to identify services that a client may need. The instrument: (1) indicates the services the client came for; (2) assesses additional service needs; and (3) records services, appointments, and referrals provided. The screening instrument was pre-tested before introduction. Experimental providers received a daylong training session that covered the use of the systematic screening instrument and the advantages of the intervention for the clinic, health system, and clients.

Prior to the intervention only the services requested and provided were recorded in all clinics after first obtaining informed consent. The same system continued in the control clinics during the post-test period. In intervention clinics, during the post-test period, the interviewer gave the client a screening form to take to the provider, and asked the client to return the form when her visit was completed. If the client wanted to receive any of the identified services, the interviewer marked the outcome on the screening form. The pre- and post-intervention forms are shown in the Appendix. The period of observation both before and after the intervention was two and a half months, from July through November 2004. 


\section{CLINIC RESULTS}

Equivalence of groups: Sixteen providers staffed the four control clinics, and 14 providers staffed the experimental clinics (two auxiliary nurse positions in experimental clinics were vacant). Pre-intervention, 100 percent of studied services were provided once per week on days reserved for preventive health services. In the post-intervention period, 94 percent of services in control clinics and 96 percent in intervention clinics were provided on preventive health days. During the pre-test, control clinics provided 3,354 services compared to 4,380 in the experimental clinics. In both sets of clinics, the most commonly provided service was vaccination (46\% in the control and 51\% in the intervention clinics), followed by distribution of iron tablets and family planning.

With the exception of a one-year difference in education, the demographic characteristics of both groups of women were similar. A total of 9,776 currently married women 15-49 years of age were interviewed/screened in the control $(4,191)$ and experimental $(5,585)$ groups during the preand post-intervention periods. The mean age of women in both intervention and control groups was 24 years pre-intervention and 25 years post. The median number of children in both groups was two. The only notable difference was that women in the control group had a median of seven years of education, while women in the intervention group had eight years of education.

Number of services per visit: During the pre-intervention period, a mean of 1.79 services per client visit were provided in the control group and 1.64 in the experimental group, indicating that services per visit were slightly lower (9\%) in the experimental clinics than in the control clinics. Post-intervention, experimental clinics increased services per visit by approximately 22 percent while in control clinics services declined by 14 percent. (A mean of 2.00 services per visit were provided in the experimental clinics and 1.53 in the control clinics.) As shown in Table 1, all differences were statistically reliable. It is also notable that, on average, more services were received pre-intervention than were initially requested.

Table 1. Services Per Visit by Group and Study Period

\begin{tabular}{|l|c|c|c|c|c|c|c|c|}
\hline & \multicolumn{5}{|c|}{ Experimental group } & \multicolumn{3}{c|}{ Control group } \\
\cline { 2 - 9 } & $\begin{array}{c}\text { Pre } \\
\left(E_{1}\right)\end{array}$ & $\begin{array}{c}\text { Post } \\
\left(E_{2}\right)\end{array}$ & $\begin{array}{c}\text { Percentage } \\
\text { Difference } \\
\left(E_{2}-E_{1}\right)\end{array}$ & $Z^{+}$ & $\begin{array}{c}\text { Pre } \\
\left(C_{1}\right)\end{array}$ & $\begin{array}{c}\text { Post } \\
\left(C_{2}\right)\end{array}$ & $\begin{array}{c}\text { Percent } \\
\text { Difference } \\
\left(C_{2}-C_{1}\right)\end{array}$ & $Z^{+}$ \\
\hline $\begin{array}{l}\text { Number of } \\
\text { women }\end{array}$ & 2,675 & 2,910 & - & & 1,999 & 2,192 & - & \\
\hline $\begin{array}{l}\text { Mean number of } \\
\text { services per woman }\end{array}$ & - & & & & \\
\hline $\begin{array}{l}\text { Services } \\
\text { Requested }\end{array}$ & $\begin{array}{c}1.01 \\
(0.11)\end{array}$ & $\begin{array}{c}1.02 \\
(0.15)\end{array}$ & 1.0 & $2.96^{\star *}$ & $\begin{array}{c}1.01 \\
(0.16)\end{array}$ & $\begin{array}{c}1.04 \\
(0.19)\end{array}$ & 3.0 & $4.71^{\star *}$ \\
\hline $\begin{array}{l}\text { Services } \\
\text { Received }\end{array}$ & $\begin{array}{c}1.64 \\
(0.75)\end{array}$ & $\begin{array}{c}2.00 \\
(0.89)\end{array}$ & 22.0 & $15.63^{\star *}$ & $\begin{array}{c}1.79 \\
(0.90)\end{array}$ & $\begin{array}{c}1.53 \\
(0.77)\end{array}$ & -14.5 & $9.63^{\star *}$ \\
\hline
\end{tabular}

${ }^{+}$Based on comparison of the mean rank for each group using the Mann-Whitney $U$ test. Figures within parenthesis indicate the standard deviation.

*** $p<.0001$ 
Statistical reliability in this study is largely an artifact of sample size. A more meaningful evaluation of the strength of the intervention is a simple comparison of percent changes in services per visit (Table 2). Services per visit in every control clinic declined during the study period, while they increased in every intervention clinic.

Table 2. Services per Visit in Control and Experimental Groups by Clinic and Period

\begin{tabular}{|c|c|c|c|c|c|c|c|}
\hline \multirow[b]{2}{*}{$\begin{array}{l}\text { Name of } \\
\text { Clinic }\end{array}$} & \multicolumn{3}{|c|}{$\begin{array}{c}\text { Pre-intervention period } \\
\text { (1 July } 2004-14 \text { September } \\
2004)\end{array}$} & \multicolumn{3}{|c|}{$\begin{array}{c}\text { Post-intervention period } \\
\text { (15 September 2004 - } 30 \\
\text { November 2004) }\end{array}$} & \multirow[b]{2}{*}{$\begin{array}{l}\text { Percent } \\
\text { change } \\
\left(M_{2}-M_{1}\right)\end{array}$} \\
\hline & $\begin{array}{l}\text { Visits } \\
\text { (N) }\end{array}$ & $\begin{array}{l}\text { Services } \\
\text { (N) }\end{array}$ & $\begin{array}{c}\text { Mean } \\
\text { services } \\
\text { per visit } \\
\left(\mathrm{M}_{1}\right)\end{array}$ & $\begin{array}{l}\text { Visits } \\
\text { (N) }\end{array}$ & $\begin{array}{l}\text { Services } \\
\text { (N) }\end{array}$ & $\begin{array}{c}\text { Mean } \\
\text { services } \\
\text { per visit } \\
\left(\mathrm{M}_{2}\right)\end{array}$ & \\
\hline \multicolumn{8}{|c|}{ Control Group } \\
\hline Navi Dharti & 329 & 425 & 1.29 & 294 & 337 & 1.15 & -11.6 \\
\hline Fatehpura & 482 & 737 & 1.53 & 717 & 840 & 1.17 & -23.5 \\
\hline Gotri & 704 & 1660 & 2.36 & 628 & 1402 & 2.23 & -5.5 \\
\hline Sawad & 484 & 750 & 1.55 & 553 & 775 & 1.40 & -9.7 \\
\hline Total & 1999 & 3572 & 1.79 & 2192 & 3354 & 1.53 & -14.5 \\
\hline \multicolumn{8}{|c|}{ Experimental Group } \\
\hline Gorva & 495 & 721 & 1.46 & 649 & 1206 & 1.86 & 27.4 \\
\hline Bauchawad & 435 & 614 & 1.41 & 444 & 680 & 1.53 & 8.5 \\
\hline Navayard & 713 & 1318 & 1.85 & 875 & 1986 & 2.27 & 22.7 \\
\hline $\begin{array}{l}\text { Old Padra } \\
\text { Road }\end{array}$ & 1032 & 1727 & 1.67 & 942 & 1935 & 2.05 & 22.8 \\
\hline Total & 2705 & 4380 & 1.64 & 2910 & 5807 & 2.00 & 21.7 \\
\hline
\end{tabular}

Method specific increases: To a large extent, the increase in total services per visit was driven by the provision of more family planning services to women who visited the clinic for vaccination of children. In the pre-intervention period, women in the control group visiting for childhood vaccination received an average of 0.37 family planning services. In the post-intervention period, the ratio was $0.36: 1$. In comparison, the ratio of family planning services to vaccination visits in the experimental group increased from $0.42: 1$ to $0.62: 1$, post-intervention.

Follow-up of detected services needs: Most women requested the needed services detected during the intervention, and experimental clinics were able to satisfy most requests during the same client visit. Table 3 shows the five principal unmet service needs that were identified during the study, the proportion of women requesting identified services, and the type of service delivery intervention (i.e., service provided at same visit, service scheduled for a future visit, or client referred to other center). 
Table 3. Service Needs Identified and Service Outcomes

\begin{tabular}{|c|c|c|c|c|c|c|c|}
\hline \multirow[t]{2}{*}{$\begin{array}{l}\text { Type of } \\
\text { Service }\end{array}$} & \multirow{2}{*}{$\begin{array}{c}\text { Number } \\
\text { Identified } \\
\text { During } \\
\text { Screening }\end{array}$} & \multicolumn{2}{|c|}{$\begin{array}{c}\text { Requested } \\
\text { Service } \\
\text { (\% and number) }\end{array}$} & \multicolumn{4}{|c|}{$\begin{array}{l}\text { Type of Intervention Among Women } \\
\text { Requesting Service ( } \% \text { and number) }\end{array}$} \\
\hline & & Yes & No & Provided & Scheduled & Referred & Total \\
\hline Family planning & 1505 & $\begin{array}{c}97.1 \\
(1461)\end{array}$ & $\begin{array}{l}2.9 \\
(44)\end{array}$ & $\begin{array}{c}99.7 \\
(1457) \\
\end{array}$ & $\begin{array}{l}0.3 \\
(4)\end{array}$ & 0.0 & $\begin{array}{c}100 \\
(1461)\end{array}$ \\
\hline Postnatal care & 128 & $\begin{array}{l}100.0 \\
(128)\end{array}$ & 0.0 & $\begin{array}{l}100.0 \\
(128)\end{array}$ & 0.0 & 0.0 & $\begin{array}{c}100 \\
(128)\end{array}$ \\
\hline Child care & 300 & $\begin{array}{l}95.0 \\
(285)\end{array}$ & $\begin{array}{l}5.0 \\
(15) \\
\end{array}$ & $\begin{array}{r}86.3 \\
(246) \\
\end{array}$ & $\begin{array}{c}4.6 \\
(13) \\
\end{array}$ & $\begin{array}{c}9.1 \\
(26) \\
\end{array}$ & $\begin{array}{l}100 \\
(285) \\
\end{array}$ \\
\hline $\begin{array}{l}\text { Reproductive } \\
\text { health }\end{array}$ & 258 & $\begin{array}{l}93.8 \\
(242)\end{array}$ & $\begin{array}{c}6.2 \\
(16)\end{array}$ & $\begin{array}{c}76.9 \\
(186)\end{array}$ & $\begin{array}{r}4.9 \\
(12)\end{array}$ & $\begin{array}{l}18.2 \\
(44)\end{array}$ & $\begin{array}{c}100 \\
(242)\end{array}$ \\
\hline Other services & 623 & $\begin{array}{c}97.3 \\
(606)\end{array}$ & $\begin{array}{c}2.7 \\
(17)\end{array}$ & $\begin{array}{c}99.8 \\
(605)\end{array}$ & $\begin{array}{l}0.2 \\
(1)\end{array}$ & 0.0 & $\begin{array}{l}100 \\
(606)\end{array}$ \\
\hline Total & 2814 & $\begin{array}{c}96.7 \\
(2722) \\
\end{array}$ & $\begin{array}{l}3.3 \\
(99)\end{array}$ & $\begin{array}{c}96.3 \\
(2622)\end{array}$ & $\begin{array}{c}1.2 \\
(30) \\
\end{array}$ & $\begin{array}{l}2.5 \\
(70)\end{array}$ & $\begin{array}{c}100 \\
(2722) \\
\end{array}$ \\
\hline
\end{tabular}

Overall, women requested services for almost 97 percent of detected needs, and 96 percent of women received requested services on the same day, in the same clinic. Actual provision ranged from 77 percent for reproductive health services to 100 percent for postnatal care.

\section{RESULTS IN ANGANWADI CENTERS}

The same design and intervention was used in the Anganwadi Centers as in the urban clinic study. There were 911 clients in the experimental group during the pre-test period and 605 in the post-test period. There were 877 pre-test control clients and 753 post-test. Client profiles were similar in both groups. Clients in the control group had a median age of 24 during the pre-test period and 25 during post-test. Experimental clients had a median age of 24 throughout the study. The median number of living children was two in both groups. The only notable difference was in education. Women visiting the experimental centers had a median of seven years of education compared to five years in the control centers.

Control AWCs provided a mean of 1.62 services per visit during the pre-test period, dropping to 1.36 during the post-test, a decline of approximately 16 percent. Intervention AWCs provided a mean of 1.48 services per visit during the pre-test and 1.61 services during the post-test, a difference of nine percent. All differences are statistically reliable $(\mathrm{p}<.05)$. As in the urban clinics, the number of family planning services showed the greatest increase.

\section{DISSEMINATION AND UTILIZATION}

Upon completion of the study, the results were presented at a seminar in Vadodara. Participants included representatives of the Vadodara municipal government and the municipal public health program, officials from Gujarat State, and local nongovernmental organizations. Briefs are being prepared for wider circulation of the results to other Indian organizations, international donors, and other Asian reproductive health programs. Vadodara announced that it would scale-up the 
intervention to all clinics in the city, while the health system in the state of Gujarat will initiate the intervention in two districts outside of Vadodara containing over 50 clinics.

\section{DISCUSSION}

Systematic screening produced a large increase in services per visit in experimental clinics at the same time that services per visit declined in the control clinics. The study also found that the systematic screening instrument produced smaller, but still non-trivial, increases at Anganwadi Centers. An early outcome of the study is that the city of Vadodara and the state of Gujarat have decided to scale-up systematic screening to other clinics. More broadly, the study has demonstrated that systematic screening is an effective mechanism for integrating services at the provider level - the level that is most meaningful in reducing clients' unmet service needs. It was also found that almost all women with previously undetected service needs requested services, and that the clinics were able to provide almost all requested services at the same visit. The results of this study are consistent with those of other studies conducted in Africa and Latin America. The systematic screening technique thus appears to be robust and useful across cultures and across service delivery systems.

Limitations of the study include the small number of clinics involved and the presence of interviewers in the clinic who may have stimulated providers to do more screening and provide more services than would otherwise be the case. However, the likelihood of this possibility must be examined in the light of the fact that interviewers were also present in the control group where services per visit actually declined. Additionally, no exit interviewers were present in the 111 Anganwadi centers (data was collected from service statistics) where results similar to those in clinics were found.

Prior to deciding the scope and pace of scaling-up, the state of Gujarat and the city of Vadodara need to estimate the costs of providing a large number of additional services and training a large number of providers. Screening clients already using clinics may be more cost-effective than recruiting new clients. Finally, providing more services at the same visit may also result in reduced financial and opportunity costs for women. 


\section{REFERENCES}

Foreit, James R., Ricardo Vernon, and Patricia Riveros Hamel. 2005. "Use of systematic screening to increase the provision of reproductive health services in Bolivia," FRONTIERS Final Report, Washington, DC: Population Council.

Foreit, Karen G. Fleischman, Karen Hardee, and Kokila Agerwal. 2002. "When does it make sense to consider integrating STI and HIV services with family planning services?” International Family Planning Perspectives 28(2): 105-107.

León, Federico et al. 1998. "Increasing use of reproductive health services in a Peruvian clinic," in Family Planning Operations Research: A Book of Readings, eds J. Foreit and T. Frejka. New York: Population Council, pp. 239-245.

Sanogo, Diouratié et al. 2005. "Using systematic screening to increase integration of reproductive health services delivery in Senegal," FRONTIERS Final Report, Washington, DC: Population Council.

Vernon, Ricardo and James R. Foreit. 1999. "How to help clients obtain more preventative reproductive health care,” International Family Planning Perspectives 25(4). 
APPENDIX

Systematic Screening Instruments 
POPULATION RESEARCH CENTRE, VADODARA

FRONTIERS, POPULATION COUNCIL, DELHI

EXIT INTERVIEW

Form A for Use in Experimental and Control clinics during Pre-intervention Period

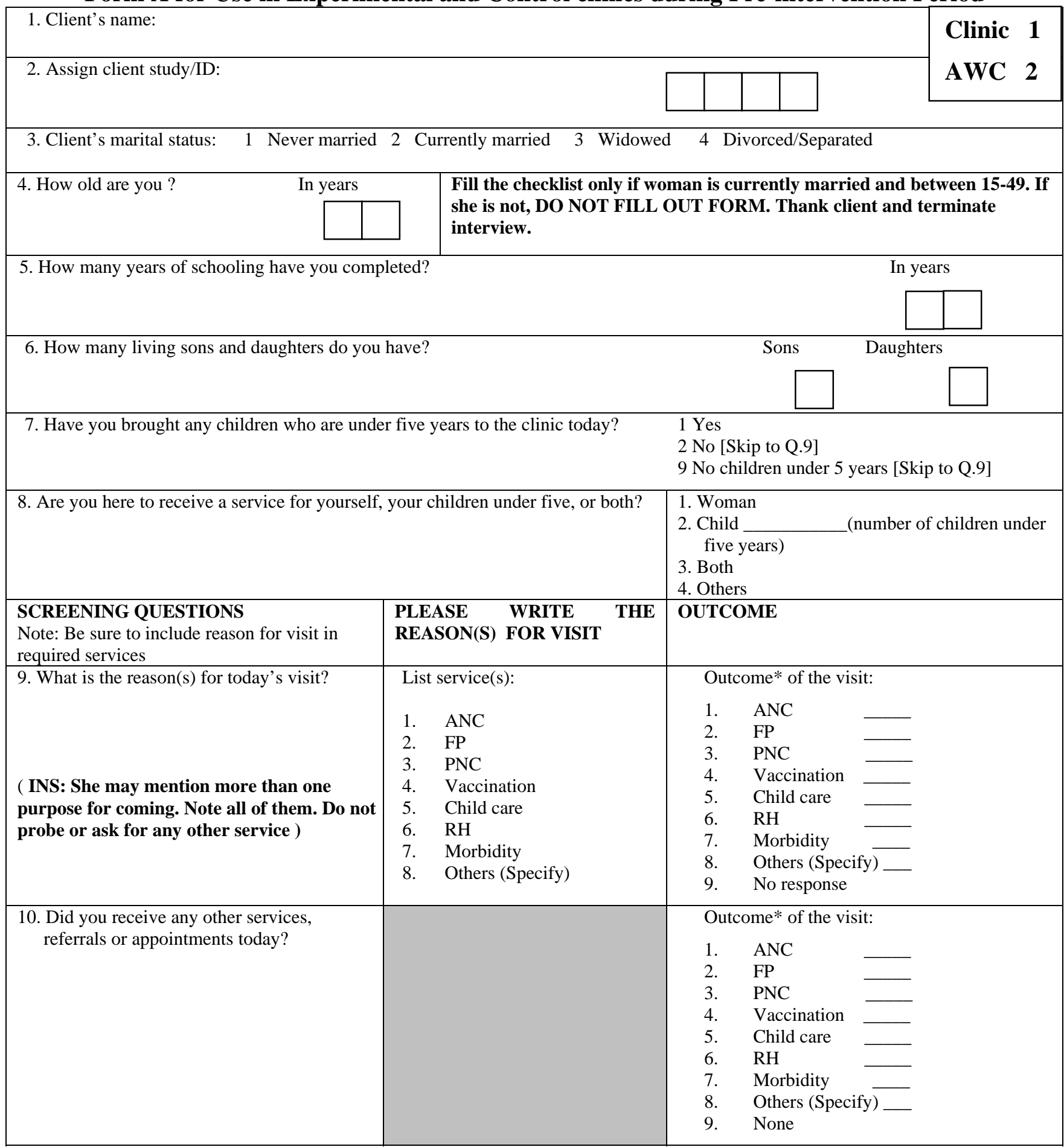

* Codes : 1. Provided 2. Scheduled 3.Referred Clinic Name: Gorva 1 Navi Dharti 2 Fatepura 3 Nawayard 7
Old Padra Road 8

\section{Not received 9. No response}

\section{Gotri 4}

Sawad 5

Bauchawad 6

Name of interviewer Today’s date: $\mathrm{d} /$ $\mathrm{m} /$ $\mathrm{yr} /$ 
STANDARD SCREENING INSTRUMENT

Form B for Experimental Clinics during Post-test Period

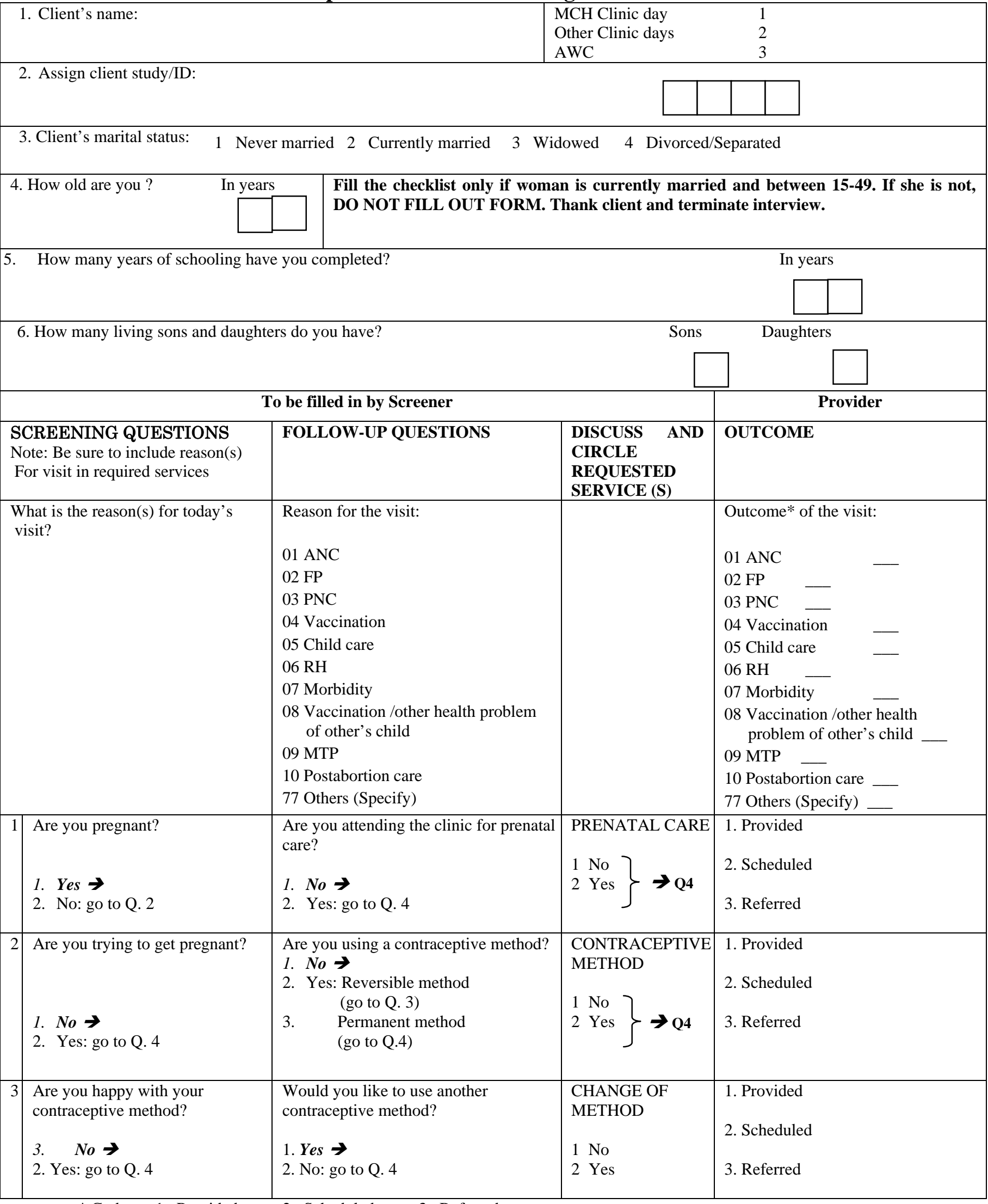

* Codes: 1. Provided

2. Scheduled

3. Referred 